\title{
FutureJournal
}

\section{Governança de TI nos Bancos de Varejo Brasileiros: Comportamento e Tendências}

\author{
Elisabete Cecilia Januario Chaves \\ Mestra em Gestão e Tecnologia em Sistemas Produtivos Centro Estadual de Educação \\ Tecnológica Paula Souza (CEETPS), Brasil \\ elisabetechaves@globo.com \\ Napoleão Verardi Galegale \\ Professor do Centro Estadual de Educação Tecnológica Paula Souza (CEETPS), Brasil \\ nvg@galegale.com.br \\ Marilia Macorin de Azevedo \\ Professora de Pós-Graduação do Centro Estadual de Educação Tecnológica Paula Souza \\ (CEETPS), Brasil \\ marilia.azevedo@fatec.sp.gov.br
}

\section{RESUMO}

A governança corporativa assim como a governança de TI continuam sendo prioridades nas organizações para sustentar suas operações e assegurar que possam implementar as estratégias necessárias para expandir suas atividades no futuro. O objetivo desta pesquisa foi analisar os resultados e as tendências de requisitos e práticas de governança de TI nos bancos de varejo no Brasil. O método survey foi utilizado na pesquisa. Três questionários foram considerados, sendo o bloco 1 com perguntas sobre os bancos e respondentes, o bloco 2 sobre requisitos para atender à governança de TI e o bloco 3 sobre as práticas implementadas e a implantar até 2017. Os questionários foram enviados para mais de cem bancos e respondentes e houve 41 respostas completas. Foi utilizada a escala Likert nas opções das alternativas. As informações coletadas foram estatisticamente analisadas utilizando: 1) análise descritiva e 2) segmentação de perfis por meio da análise de cluster. Os resultados obtidos indicam quais requisitos e práticas estão sendo utilizados pelas instituições pesquisadas; em quais fases de implantação se encontram no cenário atual, bem como qual é a previsão para implantação em 2017. Também são avaliados os 


\section{FutureJournal}

resultados sobre a adesão a essas práticas e principais benefícios dos requisitos para atender à governança de TI.

PALAVRAS-CHAVE: Governança corporativa. Governança de TI. Práticas de governança de TI. Bancos brasileiros. Análise de cluster.

\section{IT governance in the Retail Banking Forum: Behavior and Trends}

\section{ABSTRACT}

The corporate governance as IT governance are priorities for companies to sustain business operations and ensure necessary strategy implementations to expand activities in the future. The purpose of this research was to evaluate results and trends for IT governance requisites and frameworks in retail banks in Brazil. Data collection survey was used in this research. Three questionnaires were used as group 1 with questions about banks and interviewed persons, group 2 about requirements to attend IT governance and group 3 about frameworks implemented and to be implemented until 2017. Questionnaires were sent to more than 100 banks and 41 completed answers were received. It was used Likert scale in alternative options. Collected information was statistically analyzed by descriptive analysis, profile segmentation using cluster analysis. The achieved results indicate requisites and frameworks currently in use by the surveyed institutions; in which phase of Implementation the institutions searched are in the current scenario as well the implementation forecast for 2017. Additionally, the results regarding practice adhesion and main requirement benefits to attend IT governance.

KEY-WORDS: Corporate governance. IT governance. IT governance frameworks. Brazilian banks. Cluster analysis. 


\section{INTRODUÇÃO}

É importante conhecer o conceito de governança corporativa para chegar-se à relevância da governança de TI. A governança corporativa foi muito discutida, em meados de 2002, quando surgiram os escândalos financeiros da Enron, Worldcom e Tyco, entre outras empresas. Os impactos financeiros desses fatos levaram à maior preocupação em proteger os stakeholders, segundo Weill e Ross (2004). Assim, o governo americano criou uma nova legislação exigindo que os executivos das empresas atestassem pessoalmente a exatidão de seus balanços e informassem seus resultados mais rapidamente. Por essas razões, as empresas passaram a ter maior foco em governança corporativa (Weill \& Ross, 2004).

Dessa forma, a governança de TI, desde 2002, já estava mais voltada para atender às exigências regulatórias; posteriormente, constatouse que a governança de TI bem implementada, além de atender aos requisitos legais, pode aumentar o valor dos negócios (Weill \& Ross, 2006).

Devido à importância da governança de TI nas organizações, neste artigo a questão de pesquisa é: Quais requisitos e práticas de governança de TI os bancos de varejo no Brasil adotaram até 2014 e continuarão adotando ou implementarão até 2017?

\section{REVISÃO BIBLIOGRÁFICA}

\subsection{INFORMAÇÕES SOBRE O SETOR FINANCEIRO}

O setor financeiro foi escolhido para este estudo, em função do forte impacto do uso da TI sobre as operações desse setor há vários anos e, ainda hoje, talvez seja a indústria bancária a mais informatizada de todas. Nesse setor, observa-se e demonstra-se que investimentos em TI provocam crescente lucratividade, gerando redução de custos e, fundamentalmente, vantagem competitiva, como bem afirma Meirelles (2004). O uso de 
recursos e serviços de TI é fundamental para que os bancos possam ter melhor posição competitiva no mercado (Cordenonsi, 2004).

No relatório da Ciab Febraban (2013) há relatos de que os investimentos em tecnologia continuam crescendo no Brasil, nos últimos anos, totalizando cerca de $\mathrm{R} \$ 20$ bilhões em 2012. O Brasil é um dos principais participantes da tecnologia bancária no mundo, e o tema governança de TI permanece sendo fundamental para garantir o crescimento e a operacionalização dos negócios.

O setor financeiro vem investindo de forma crescente em tecnologia, e ainda há muito espaço para novos investimentos em Tecnologia da Informação e Comunicação (TIC), conforme dados de levantamento realizado pela Febraban (2013a), em parceria com a Booz \& Company, junto às principais instituições financeiras do país. Nele é citado que o setor financeiro é um dos que mais investem em tecnologia. Em 2012, essas empresas gastaram mais de R $\$ 20$ bilhões com TI, dando um salto de R\$ 8 bilhões em relação aos valores de 2008. A taxa de crescimento anual do gasto com TI tem sido aproximadamente de 10\%. Dessa forma, o Brasil é um dos principais mercados de tecnologia bancária no mundo, pois, de todo gasto com tecnologia no País, 15\% vêm do segmento financeiro.

Nesse sentido, os temas governança corporativa e governança de TI seguem primordiais para o desenvolvimento e o crescimento das aplicações de forma segura e auditável para o setor bancário brasileiro. A pesquisa Ciab Febraban (2013), também publicou os principais drivers (direcionadores) para os bancos. Pode-se notar no Quadro 1 a demonstração dos drivers de negócio, drivers para tecnologia e principais temas, correspondentes, que têm como foco o crescimento em novos mercados, a expansão em mercados existentes, a redução de custos e controles e a auditoria, uma vez que estes demonstram que a governança corporativa e a governança de TI continuam na lista das prioridades dos bancos. 


\begin{tabular}{|c|c|c|}
\hline $\begin{array}{l}\text { Drivers de } \\
\text { Negócio }\end{array}$ & Drivers de Tecnologia & Principais Temas \\
\hline $\begin{array}{l}\text { Crescimento em } \\
\text { novos mercados }\end{array}$ & Plataformas comuns escaláveis & $\begin{array}{l}\text { Plataformas e soluções comuns } \\
\text { e escaláveis } \\
\text { Interoperabilidade } \\
\text { Flexibilidade para mudanças }\end{array}$ \\
\hline $\begin{array}{l}\text { Expansão nos } \\
\text { mercados } \\
\text { existentes }\end{array}$ & $\begin{array}{l}\text { Maior acessibilidade e funcionalidade } \\
\text { dos canais }\end{array}$ & $\begin{array}{l}\text { Acessibilidade } \\
\text { Facilidade de uso }\end{array}$ \\
\hline $\begin{array}{l}\text { Satisfação dos } \\
\text { clientes }\end{array}$ & $\begin{array}{l}\text { Visão única do cliente e } \\
\text { conhecimento/ análise dos } \\
\text { comportamentos }\end{array}$ & Foco no cliente \\
\hline Redução dos custos & $\begin{array}{l}\text { Sourcing de TI para reduzir custos } \\
\text { Agilidade/automação dos processos } \\
\text { de negócios para reduzir custos }\end{array}$ & Eficiência e custos \\
\hline Controle e auditoria & Controle e gestão de riscos & $\begin{array}{l}\text { Segurança e gestão de riscos } \\
\text { Governança }\end{array}$ \\
\hline
\end{tabular}

\section{Quadro 1: Principais drivers da arquitetura no setor bancário}

Fonte: adaptado de Ciab Febraban (2013)

\subsection{GOVERNANÇA DE TI}

A governança de TI, braço da governança corporativa, segundo o Instituto Brasileiro de Governança Corporativa (IBGC), tem o papel de criar controles para que a TI trabalhe de maneira a mais transparente possível perante os stakeholders (executivos, conselho de administração, acionistas).

Com o surgimento do Sarbanes Oxley Act em 2004, a TI teve de preparar-se para gerar informações de controles de sistemas e tecnologias. Os CIOs (Chief Information Officer) precisaram ter planejamento e recursos para atender a essas exigências, não só definindo quais tecnologias podem ajudar, mas também desenvolvendo planos para atender aos controles internos para a empresa. (Ruzbacki, 2004).

Para aprofundar o entendimento sobre o tema governança de TI, neste trabalho realizou-se um estudo bibliométrico buscando verificar a produção científica dos autores em livros, anais de congressos e periódicos que tratam de governança de TI.

Vanti (2002) indica que a bibliometria é composta por um conjunto de métodos de pesquisa utilizados pela área de Ciências da Informação que utilizam a análise quantitativa de dados para delinear determinado campo 
de estudo e também para analisar como a construção do conhecimento está relacionada com o comportamento dos pesquisadores.

Apesar de permitir diversas análises como a dispersão geográfica da produção do conhecimento, a evolução da importância de determinado tema em função do tempo, neste trabalho utilizou-se a bibliometria para identificar os principais expoentes em governança de TI para compor seu referencial teórico.

Como parâmetros para realização deste estudo bibliométrico, foram consideradas as publicações em livros, anais de congressos e periódicos, nacionais e internacionais, entre os anos de 2000 e 2015.

Foi utilizado como base primária de pesquisa o Google Scholar, mas acessaram-se também as bases Web of Science e Scopus, por meio da ferramenta Publish or Perish, de Harzing (2007).

Foram utilizadas as seguintes expressões de busca nos campos assunto, palavras-chave e resumo, em inglês com sua respectiva tradução para português:

- $\quad$ IT Governance / Governança de TI;

- Information Technology Governance / Governança da Tecnologia da Informação

Aplicando-se todos os parâmetros apresentados, foram identificados 760 resultados únicos, os quais passaram por um refinamento exploratório para descartar aqueles que não pertencem ao assunto pesquisado, chegando a 735 resultados únicos relevantes.

No Gráfico 1, a seguir, é apresentada a evolução anual da quantidade de publicações entre os anos 2000 e 2015 


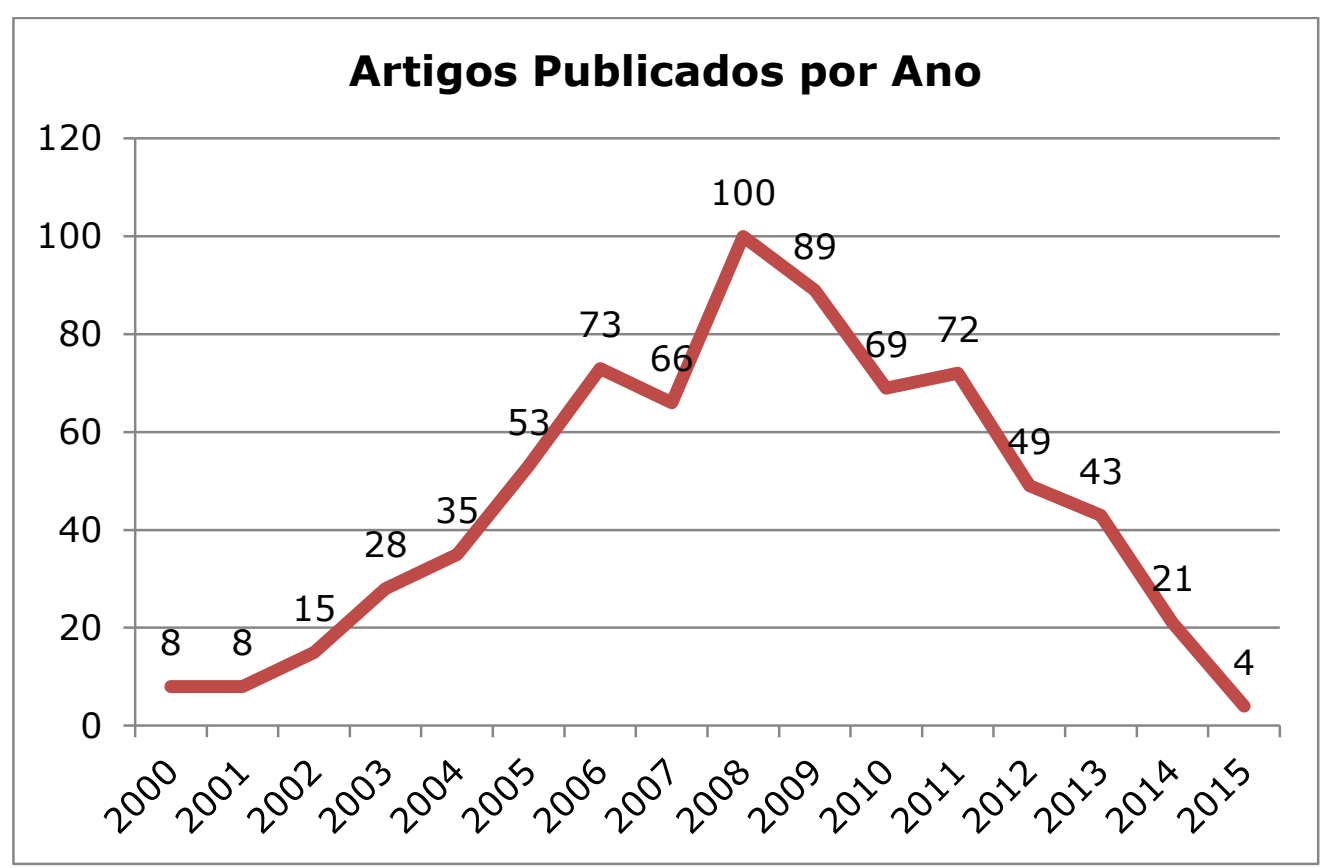

\section{Gráfico 1: Produção anual de livros, artigos e anais de congresso sobre governança de TI}

Fonte: os autores

É possível observar que houve um aumento considerável de publicações desde o ano 2000, o que reflete em parte os problemas apresentados na introdução deste trabalho.

Também foi realizada a análise da quantidade absoluta de citações de cada artigo, buscando identificar os trabalhos mais relevantes sobre o assunto. No Quadro 2, são apresentados os cinco documentos mais citados, ordenados de forma decrescente.

\begin{tabular}{|c|l|l|l|}
\hline $\begin{array}{c}\text { Quantidade } \\
\text { de } \\
\text { citações }\end{array}$ & \multicolumn{1}{|c|}{$\begin{array}{c}\text { Ano de } \\
\text { publicação }\end{array}$} & \multicolumn{1}{|c|}{ Autor } & \multicolumn{1}{c|}{ Título } \\
\hline 1851 & 2004 & $\begin{array}{l}\text { P. Weill, \& J. W. } \\
\text { Ross }\end{array}$ & $\begin{array}{l}\text { IT governance: How top performers } \\
\text { manage IT decision rights for superior } \\
\text { results }\end{array}$ \\
\hline 958 & 2004 & J. Luftman & $\begin{array}{l}\text { Assessing business-IT alignment } \\
\text { maturity }\end{array}$ \\
\hline 823 & 2006 & $\begin{array}{l}\text { J. Luftman, R. } \\
\text { Kempaiah, \& E. }\end{array}$ & Kash \\
\hline 527 & 2004 & P. Weill & $\begin{array}{l}\text { Don't just lead, govern: how top- } \\
\text { performing firms govern IT }\end{array}$ \\
\hline 511 & 2003 & J. N. Luftman & $\begin{array}{l}\text { Competing in the information age: } \\
\text { align in the sand }\end{array}$ \\
\hline
\end{tabular}

Quadro 2: Documentos com maior quantidade absoluta de citações

Fonte: os autores 
O trabalho mais citado, "IT governance: How top performers manage IT decision rights for superior results", de Weill e Ross (2004), pode ser considerado um dos mais relevantes do campo e possui mais citações que as próximas duas obras combinadas. Foi um marco em formalizar a governança de TI aliando as teorias a levantamentos empíricos e verificando como as empresas que alcançam bons resultados implantaram os conceitos de governança de TI. Essa obra é utilizada como principal referência ao longo deste trabalho.

O próximo trabalho da lista, "Assessing business-IT alignment maturity" (Luftman, 2000), aborda como a governança de TI auxilia a empresa a alinhar estrategicamente as ações de TI e de negócio de forma a atingir seus objetivos. Essa constatação também está presente no trabalho de Weill e Ross (2004), reforçando a tese de que esse alinhamento não só é benéfico para o resultado da empresa como é um objetivo a ser alcançado.

Ainda de Luftman et al. (2006), o trabalho "Key issues for IT executives 2005" apresenta os resultados da pesquisa realizada com 105 executivos de empresas, que identificou serem estas as maiores preocupações dos CIOs em 2005: i) alinhamento entre TI e negócio; ii) atração, desenvolvimento e retenção de profissionais de TI; iii) segurança e privacidade; iv) planejamento estratégico de TI; e v) reengenhaira de processos de negócio. Esta é uma pesquisa recorrente que, em uma de suas edições mais recentes, manteve o "alinhamento estratégico entre TI e negócio" como uma preocupação constante entre os CIOs.

Os próximos trabalhos mais citados de Weill (2004) e Luftman (2003) mantêm o foco no alinhamento estratégico, permitindo concluir que a Governança de TI está definitivamente conectada a este tópico.

Buscando obter uma visão mais prática sobre o assunto, verificou-se que no relatório Global Status Report on the Governance of IT (GEIT) - do Information Technology Governance Institute - Information Systems Audit and Control Association (ITGI - ISACA, 2011) - que é uma pesquisa feita com 834 executivos de TI em 21 países, em dez setores de negócios em pequenas e grandes empresas, foram apresentados alguns resultados importantes para o tema governança de TI, tais como: i) investimentos de TI criarem valores para o negócio; ii) importância do papel dos gestores de 
TI nas organizações; foco da governança para TI estar alinhada aos objetivos dos negócios; iii) aumento do outsourcing, principalmente nas grandes empresas para atingir estratégias de negócios; iv) aumento do uso de cloud computing; v) despesas de TI estarem visíveis; vi) redução de fornecedores, staff permanente, consolidação da infraestrutura e utilização de redes sociais por funcionários.

\subsection{REQUISITOS PARA GOVERNANÇA DE TI}

Os trabalhos do Massachussets Information Technology (MIT) sobre governança de TI são referências importantes sobre este tema no cenário mundial.

Weill e Ross (2006) descrevem os resultados de pesquisas feitas em 256 empresas de todo o mundo em 32 estudos de casos em vários setores, em empresas com e sem fins lucrativos, sobre o tema governança de TI. Ressalta-se que Peter Weill é diretor do Center for Information Systems Research (CISR) e pesquisador cientista sênior da Sloan School of Management do Massachusetts Institute (MIT Sloan). Já Jeanne W. Ross é a principal pesquisadora do CISR.

A pesquisa realizada por esses autores aponta que as empresas com boa governança de TI podem atingir até $20 \%$ da lucratividade, que representa percentual superior ao atual.

Weill e Ross (2004) afirmam que o valor de negócios de TI resulta de uma boa governança de $\mathrm{TI}$, relativa à alocação de responsabilidades $\mathrm{e}$ direitos decisórios. Os autores apresentam o framework do MIT-CISR, que é bastante aplicável em projetos de implementação de governança de TI.

Weill e Ross (2004) mencionam que toda empresa necessita definir cinco decisões inter-relacionadas sobre a área de tecnologia da informação:

- $\quad$ princípios de TI - são declarações de alto nível sobre como a TI é utilizada nos negócios;

- $\quad$ arquitetura de TI - referem-se à organização das informações, aplicações e infraestrutura, definidas a partir de políticas, relacionamentos e diferentes técnicas para padronização e integrações dentro de TI; 
- infraestrutura de TI - serviços de TI coordenados, compartilhados e referentes à capacidade de TI;

- $\quad$ necessidades de aplicações de negócios - são desenvolvidas internamente ou por parceiros externos;

- $\quad$ investimentos e priorização dos projetos e atividades de TI, isto é, decisões sobre em que investir e quanto investir, utilizando justificativas e aprovações técnicas.

Já Peterson (2004b) cita que existe preocupação quanto à relação entre os investimentos e as tecnologias e como estes têm sido gerenciados. Tais fatos têm feito com que tanto executivos de tecnologia quanto de negócios reconheçam que o sucesso da TI, atualmente, não está na tecnologia em si, mas sim na forma como ela é governada.

O alinhamento estratégico de TI deve estar focado nas estratégias e objetivos organizacionais, como aponta Luftman (2000). O grau de maturidade desse alinhamento traz um comprometimento entre TI e as áreas de negócios, para adotarem estratégias em conjunto e de forma integrada.

Uma área de governança de TI ou a definição de responsabilidades que garantam a governança de TI propiciam o alinhamento estratégico de TI.

Segundo Van Grembergen, De Haes e Guldentops (2004), a governança de TI caracteriza-se por uma combinação de diferentes práticas associadas à estrutura, aos processos e aos mecanismos de relacionamento.

Os mecanismos de governança de TI lidam com processos ligados a monitoramento, planejamento e decisões estratégicas da TI. Em tais mecanismos estão não só as práticas ligadas ao controle da tecnologia, como também a definição de processos, procedimentos e políticas que permitam que a empresa possa medir, monitorar e avaliar sua situação seguindo alguns fatores, critérios e melhores práticas predefinidas. (Webb, Pollard \& Ridley, 2006).

No Quadro 3, pode-se observar um resumo dos mecanismos ligados à boa governança de TI. 


\begin{tabular}{|c|c|c|}
\hline ESTRUTURAS & PROCESSOS & $\begin{array}{l}\text { MECANISMOS DE } \\
\text { RELACIONAMENTOS }\end{array}$ \\
\hline - Papéis e responsabilidades & $\begin{array}{l}\text { - Indicadores de } \\
\text { Desempenho de TI }\end{array}$ & $\begin{array}{l}\text { - Participação Ativa de } \\
\text { Principais Stakeholders }\end{array}$ \\
\hline - Comitê de Estratégia de TI & $\begin{array}{l}\text { - Planejamento Estratégico } \\
\text { de Sistemas de Informação }\end{array}$ & - Incentivos e Recompensas \\
\hline - Comitê Diretivo de TI & - COBIT & $\begin{array}{l}\text { - Colocação de TI e de } \\
\text { Negócios }\end{array}$ \\
\hline $\begin{array}{l}\text { - Estrutura Organizacional } \\
\text { de TI }\end{array}$ & - ITIL & $\begin{array}{l}\text { - Compreensão } \\
\text { Compartilhada dos Objetivos } \\
\text { de TI e de Negócios }\end{array}$ \\
\hline $\begin{array}{l}\text { - CIO no Conselho de } \\
\text { Administração }\end{array}$ & $\begin{array}{l}\text { - Acordos de Nível de } \\
\text { Serviço }\end{array}$ & - Resolução Ativa de Conflitos \\
\hline - Comitê de Projetos de TI & $\begin{array}{l}\text { - Métodos de Avaliação de } \\
\text { Retorno de Investimento }\end{array}$ & $\begin{array}{l}\text { - Treinamento Interfuncional } \\
\text { entre TI e Negócios }\end{array}$ \\
\hline - Escritório de Projetos & - Avaliação Ex Post & $\begin{array}{l}\text { - Rotação de Tarefas de TI e } \\
\text { Negócios }\end{array}$ \\
\hline
\end{tabular}

\section{Quadro 3: Estruturas, processos e mecanismos de relacionamento na governança de TI}

Fonte: Peterson (2004a)

Segundo Lunardi (2008), os mecanismos e as práticas visam facilitar a implantação de modelos de governança de TI, considerando a estrutura que envolve as decisões para TI, os processos e as habilidades de relacionamento para gerenciar as atividades ligadas ao planejamento, à organização e ao controle de TI.

Albertin e Albertin (2010) também apresentam fatores importantes para o processo de decisão, tais como: participação da alta administração; participação da organização com corresponsabilidade entre TI e negócios; alinhamento estratégico; influências de TI nas decisões; regras e procedimentos para monitorar decisões estratégicas de investimentos; centralização, risco e qualidade de serviços; gerenciamento do conhecimento.

\subsection{PRÁTICAS DE GOVERNANÇA DE TI}

Existem várias práticas sugeridas para a boa governança de TI que são abordadas no decorrer deste artigo. O tema segurança tem destaque 
crescente em todos os segmentos de negócios e fundamentalmente no bancário. Por essa razão, neste artigo enfoca-se esse tema.

\subsubsection{NBR ISO/IEC 17799 e NBR ISO/IEC 27001- 27002}

A ISO/IEC 27001 é um padrão para sistema de gestão da segurança da informação (Information Security Management System ISMS), publicado em outubro de 2005 pelo International Organization for Standardization (ISO) e pelo International Electrotechnical Commision (IEC). O padrão ISO/IEC 27001:2005 significa: Tecnologia da informação técnicas de segurança sistemas de gerência da segurança da informação, requisitos mais conhecidos como ISO 27001.

Posteriormente, aparece a ISO 27002 (conhecida antes como ISO 17799), que é uma norma internacional contendo controles para a Segurança da Informação. Esta ISO considera a tríade: confidencialidade garantir que a informação seja acessível somente a pessoas autorizadas; integridade - garantia da exatidão e integridade das informações e métodos de processamento; disponibilidade - garantia de que os usuários autorizados tenham acesso a informações e ativos associados quando necessário (ABNT, 2005).

Já a ISO/IEC 38500 apresenta o seguinte conceito na Nota do item 2.2.: "A responsabilidade por aspectos específicos de TI pode ser delegada aos gerentes da organização. No entanto, a responsabilidade pelo uso e entrega aceitável, eficaz e eficiente da TI pela organização permanece com os dirigentes e não pode ser delegada".

A ISO 31000:2009, Gestão de riscos Princípios e diretrizes estabelece princípios, estrutura e um processo de gestão do risco. Esta norma pode ajudar as organizações a aumentarem a probabilidade de alcançar objetivos, melhorar a identificação de oportunidades e ameaças e alocar e usar os recursos para o tratamento de riscos. 


\subsubsection{PMI e PMBoK}

O PMI (Project Management Institute), que conta com mais de 500.000 associados em 185 países, é uma grande associação profissional em Gerenciamento de Projetos. Seus associados são indivíduos que praticam e estudam o Gerenciamento de Projeto nas mais diversas áreas.

No site do PMI, "Capítulo São Paulo Brasil" (2013), o principal documento do PMI, A Guide to the Project Management Body of Knowledge (PMBoK Guide), é um padrão globalmente reconhecido para o Gerenciamento de Projetos nos mercados de hoje.

\subsubsection{COBIT}

Segundo o ITGI (2012), o Control Objectives for Information and related Technology (COBIT) fornece práticas utilizando um modelo de domínios e processos e atividades estruturadas de forma gerenciável. Elas são mais focadas no controle do que na execução. Essas práticas visam a otimizar os investimentos, garantir a entrega dos serviços e gerar métricas para o acompanhamento das atividades.

Os principais componentes do COBIT 4.0 estão organizados em quatro domínios e 34 processos de TI. Os quatro domínios do COBIT 4.0 são: Planejar e Organizar (PO), Adquirir e Implementar (AI), Entregar e Suportar (DS) e Monitorar e Avaliar (ME).

O COBIT 5 está baseado em cinco princípios, que são: satisfazer as expectativas dos stakeholders, separar governança de gestão, habilitar uma visão holística, framework integrador e cobrir o negócio como um todo.

\subsubsection{ITIL (Information Technology Infrastructure Library)}

O Information Technology Service Management Forum (itSMF, 2013) define o ITIL como "um dos exemplos mais completos de melhores práticas, a biblioteca de infraestrutura em TI tem a forma de uma coleção de livros, em que estão décadas de experiência de empresas no gerenciamento de serviços de TI". 
O itSMF é uma entidade criada e mantida em conjunto pela indústria, pelos usuários e por profissionais da área, que trabalham para o desenvolvimento e a disseminação do ITIL desde 1991. O gerenciamento dos rumos do ITIL é tratado pela parceria entre o itSMF e o Office of Government Commerce (OGC), órgão que sucedeu o Central Computer and Telecomunication Agency (CCTA) (ITSMF, 2013).

As práticas do ITIL, versão 3, são detalhadas em cinco publicações base, que fornecem uma abordagem para a gestão de serviços de TI, permitindo às empresas prestarem serviços adequados e garantirem que esses serviços correspondam aos objetivos de negócio e proporcionem benefícios.

Essas cinco publicações correspondem às cinco fases do Ciclo de Vida de Serviços ITIL: Estratégias de Serviços; Arquitetura de Serviços; Transição de Serviços; Operação de Serviços; e Melhorias Contínuas de Serviços.

\subsubsection{CMMI (Capability Maturity Model Integration)}

O Capability Maturity Model Integration (CMMI) é um modelo de referência que contém práticas "genéricas ou específicas" necessárias à maturidade em disciplinas específicas: Systems Engineering (SE), Software Engineering (SW), Integrated Product and Process Development (IPPD), Supplier Sourcing (SS). Esse modelo foi desenvolvido pelo Software Engineering Institute (SEI) da Universidade Carnegie Mellon, localizada em Pittsburgh, no estado da Pensilvânia. O CMMI é uma evolução do CMM (Capability Maturity Model) e procura estabelecer um modelo único para o processo corporativo de melhoria, integrando diferentes modelos e disciplinas. Surgiu na década de 1980 como um modelo para avaliação de risco na contratação de empresas de software pelo Departamento de Defesa dos Estados Unidos, que constituiu junto à Carnegie Mellon University o SEI, responsável pela evolução da família CMM, e, ainda, realiza diversas outras pesquisas em engenharia de software (CMMI, 2013).

Os processos de melhoria nasceram de estudos realizados por Deming, Crosbye Juran, cujo objetivo principal é a melhoria da capacidade 
dos processos, isto é, a habilidade com que estes alcançam o resultado desejado (CMMI, 2013).

O processo inclui três disciplinas: engenharia de sistemas, engenharia de software e engenharia de hardware.

\section{METODOLOGIA}

Neste trabalho, utiliza-se uma pesquisa descritiva e bibliográfica sobre o tema. Na pesquisa descritiva, como o próprio nome define, descreve-se o objeto de pesquisa, procurando descobrir a frequência com que um fenômeno ocorre, sua natureza, características, causas, relações e conexões com outros fenômenos. Neste tipo de pesquisa não há a interferência do pesquisador (Barros \& Lehfeld, 2007, p. 84). A pesquisa bibliográfica fornece o embasamento teórico necessário ao assunto, auxiliando na busca de variáveis para maior completude sobre o tema pesquisado.

A abordagem de pesquisa é quantiqualitativa, ou seja, engloba tanto a pesquisa quantitativa quanto qualitativa. A pesquisa quantitativa é "uma modalidade de pesquisa na qual as variáveis predeterminadas são mensuradas e expressas numericamente (...). A pesquisa qualitativa é uma modalidade de pesquisa na qual os dados são coletados através de interações sociais e analisados subjetivamente pelo pesquisador". (Appolinário, 2011, p. 149-150).

Para a composição do estudo, foi utilizada uma população de aproximadamente cem bancos e respondentes, considerando-se o conceito de população, segundo Bussab e Morettin (2002), não só como um conjunto de elementos ou resultados investigados, como também amostra, como sendo um subconjunto da população.

Os cem bancos e respondentes da pesquisa estão classificados por tipo, origem, naturalidade e porte dos bancos de varejo no Brasil, seguindo: a) lista publicada pela revista Valor Econômico (2013), na matéria com o título "Valor 1000", dos 100 maiores bancos do Brasil; b) lista de instituições em funcionamento do Banco Central do Brasil (BCB, 2014); c) lista da Federação Brasileira de Bancos (Febraban, 2013b). 
- Tipo: múltiplo, comercial, caixa, investimento, leasing e financeira.

- Origem: privado e público.

- Naturalidade: nacional, nacional com participação estrangeira, nacional com controle estrangeiro, estrangeiro, estadual e federal.

- Porte: o porte dos bancos segue a classificação do Banco Nacional de Desenvolvimento Social (BNDES, 2014) aplicável em todos os setores: grande, médio-grande, médio, pequeno, microempresa, como mostra o Quadro 4.

\begin{tabular}{|ll|}
\hline Classificação & Receita operacional bruta anual \\
\hline Microempresa & Menor ou igual a $R \$ 2,4$ milhões \\
Pequena & Maior que $R \$ 2,4$ milhões e menor ou igual a $R \$ 16$ \\
Média empresa & Maior que $R \$ 16$ milhões e menor ou igual a $R \$ 90$ \\
Média-grande & Maior que $R \$ 90$ milhões e menor ou igual a $R \$ 300$ \\
Grande empresa & Maior que $R \$ 300$ milhões \\
\hline
\end{tabular}

\section{Quadro 4: Classificação de portes de empresas por receita operacional bruta anual}

Fonte: BNDES (2013)

Para a coleta dos dados, foi usado o levantamento survey, que consiste em um método sistemático de coleta de informações de entidades (uma amostra), com a finalidade de construir um resumo quantitativo de características dos atributos de uma população mais ampla, da qual as entidades são membros (Groves et al., 2004). Escolheu-se a survey para levantar informações visando compreender como a governança de TI está sendo implementada no setor bancário pesquisado. Para tanto, foram realizados questionários cujas respostas se tornaram as fontes de evidências, do mesmo modo que foram utilizadas as estatísticas do setor e as informações dos bancos pesquisados.

Os questionários foram disponibilizados por e-mail, utilizou-se o link da Survey Monkey (plataforma de gerenciamento de questionários online) e as redes sociais (Linkedin, Facebook) para mais de cem bancos de varejo e respondentes. Os questionários foram enviados para diretores, gerentes e analistas das áreas de TI, Segurança, Riscos e Auditoria, entre outras áreas, em conformidade com a organização das estruturas dos bancos pesquisados para atender à governança de TI nas instituições. 
Tanto nos e-mails como nos grupos de discussão e link web Survey Monkey, uma carta de apresentação foi enviada às instituições e respondentes, informando o objetivo da pesquisa. Igualmente, houve o apoio do ISACA (Information Systems Audit and Control Association) no envio de e-mails para seus associados, solicitando a participação na pesquisa.

Os questionários foram elaborados com base na construção da Escala Likert, também conhecida como Escalonamento de Likert, um método desenvolvido por Rensis Likert em 1932 (Bertran, 2009).

Para a construção dos questionários, foram adotados os seguintes passos:

I) levantamento de vários blocos de informações consideradas importantes no estudo e descritos na fundamentação teórica;

II) desenvolvimento dos questionários com foco nos respondentes;

III) utilização da pontuação de 0 a 10 pontos;

IV) somatório final da pontuação, para selecionar os pontos que indicam as tendências mais e menos aderentes consideradas pela maioria dos respondentes.

Para análise dos dados da escala, optou-se pelo somatório de pontuação individual e faixas que indicam a atitude do respondente com relação às afirmações apresentadas. A Escala Likert deste trabalho foi construída em dois quesitos.

No que concerne aos "Requisitos para governança de $\mathrm{TI}^{\prime}$, foram utilizados, numa escala de 0 a 10, os seguintes pontos: $0=$ Não sei, 1,2 a 9= Raríssimo; 10= Muito utilizado. Cenário Atual (0 a 10) / Previsão para 2017 (0 a 10).

Para "Status / prática de governança de TI", foram utilizados, numa escala de 0 a 10, os seguintes pontos: $0=$ Não sei, 1 , 2 a $9=$ Inexistente; $10=$ Totalmente implantado. Cenário Atual (0 a 10)/ Previsão para 2017 (0 a 10).

Cabe ressaltar que nos resultados o software estatístico Statistical Package for the Social Sciences (SPSS) utilizado na pesquisa, no caso da 
"não escolha do status pelo respondente", implica exclusão automática da tabela.

Os questionários para a pesquisa foram elaborados em três blocos.

- Bloco 1 - Informações sobre os bancos e os respondentes, para melhor compreensão das respostas disponibilizadas.

- Bloco 2 - Questões sobre requisitos para atender à governança de TI de forma eficaz, segundo autores renomados em governança de TI e referenciados na fundamentação teórica. Foram feitas as questões de 7 a 21 conforme segue:

Questão 7 - Há uma área com funções e responsabilidades claras para governança de TI (assegurar alinhamento estratégico da TI e visibilidade para diretoria sobre o assunto)? (ITGI, 2003; Luftman, 2000; Cordenonsi, 2004).

Questão 8 - Há controles para compliance e riscos (planos, sistemas e processos com testes de controles aplicados a TI, auditorias internas e externas, proteção dos ativos de TI, confidencialidade, plano de continuidade dos negócios e avaliação da concorrência)? (ITGI, 2003; D 'Andrea, 2004).

Questão 9 - As decisões são tomadas de forma compartilhada e os processos de governança e alinhamento são adequados (TI e negócios participam de comitês executivos, comitê de arquitetura participa de assuntos de negócios, há comunicação entre TI e negócios sejam analistas para relacionamento ou outros, há escritórios de projetos)? (Venkatraman, 1994; Luftman, 2000; Peterson, 2004b; ITGI, 2005; Weill \& Ross, 2006; Albertin \& Albertin, 2010).

Questão 10 - A governança de TI cria valor para o negócio (custo/benefício, crescimento, utilização de ativos, flexibilidade dos negócios, outros)? (Venkatraman, 1994; Weill \& Broadbent, 1998).

Questão 11 - A governança de TI atende aos requisitos legais para o negócio (Basileia, Sarbanes Oxley, Coso, coso 2, outros)? (Ruzbacki, 2004; Fitzpatrick, 2005; Fernandes \& Abreu, 2010).

Questão 12 - Os princípios de TI são definidos e claros na empresa (modelo operacional, papel de TI, comportamentos desejáveis para TI, custos de TI, plano estratégico para TI)? (Peterson, 2004a; Weill \& Ross, 2006).

Questão 13 - A arquitetura de TI é definida e adequada (como os 
principais processos e informações se inter-relacionam, padronizações e opções tecnológicas)? (Weill \& Ross, 2006).

Questão 14 - As necessidades de aplicações de negócios são priorizadas para serem feitas ou compradas em TI adequadamente (oportunidades, inovações ou processos são atendidos em novas aplicações, validações técnicas e aceites dos requisitos pelos usuários são executados, há gerenciamento de desenvolvimento interno ou externo, há metodologias de desenvolvimento, as medidas de sucesso são acompanhadas e avaliações pós-implementações pelos responsáveis)? (Peterson, 2004a; Weill \& Ross, 2006.

Questão 15 - A infraestrutura atende às necessidades do negócio (serviços mais críticos (dados, comunicações, redes, segurança, canais eletrônicos), há planos de atualizações de hardware e terceirizações, as quantidades são adequadas)? (Venkatraman, 1994; Weill \& Ross, 2006).

Questão 16 - Os investimentos e as priorizações para TI são feitos adequadamente (critérios para priorizações (controle de custos/benefícios, crescimento, utilização de ativos, flexibilidade para negócio, lucro, incluindo VPL, ROI, TIR, ROE, ROA, etc.), portfólios atendem aos objetivos estratégicos da empresa, acompanhamento e mensuração de resultados gerados no decorrer dos projetos e alocação de custos pelos serviços utilizados ou compartilhados)? (Van Grembergen et al., 2004; Weill \& Ross, 2006).

Questão 17 - Há indicadores para acompanhamento dos serviços, das atividades e dos projetos para a empresa (Service Level Agreement (SLA), disponibilidade, capacidade, reúso, eficiência, taxa de entrega, satisfação do cliente, sustentabilidade, entre outros)? (Peterson, 2004a; Van Grembergen et al., 2004; ITGI, 2005; Kaplan \& Norton, 2006).

Questão 18 - Há planos de treinamentos de recursos humanos para TI e negócios no que tange a atividades de projetos e operações (habilidades e competências), como também treinamentos para rotatividade de atividades entre TI e negócios e quantidade de recursos adequados? (Peterson, 2004a; Van Grembergen et al., 2004).

Questão 19 - As abordagens de comunicação são adequadas (desempenho dos indicadores de TI, comunicados de TI para alta gerência, escritório de projetos ou governança, gestão do conhecimento, portais ou intranets informativos para toda empresa)? (Peterson, 2004a; Van Grembergen 
et al., 2004; Weill \& Ross, 2004).

Questão 20 - A gestão de projetos e serviços é adequada (catálogo de serviços, configurações, entregas no tempo e qualidade esperadas, tratamento de incidentes e problemas, gestão de mudanças, gerenciamento de terceiros e contratos, como também recompensas e incentivos para as equipes)? (Weill \& Ross, 2004; OGC, 2008 (ITIL)).

Questão 21 - Existe um framework/metodologia que atenda à governança de TI de forma mais completa e integrada na empresa, incluindo integrações com clientes e fornecedores? (ITGI, 2005 (COBIT); OGC, 2008 (ITIL).

- Bloco 3 - Aborda as principais práticas de governanças de TI atualmente implementadas e a serem implementadas até 2017, contempladas na fundamentação teórica e com priorização das mais relevantes segundo dados de pesquisas. Foram feitas as questões de 22 a 29 conforme segue:

Questão 22 - COBIT 4.1

Questão 23 - COBIT 5

Questão 24 - ITIL v.2 e v.3

Questão 25 - PMBoK

Questão 26 - NBR ISO/IEC 17799/27001/27002

Questão 27 - NBR ISO/IEC 31000

Questão 28 - NBR ISO/IEC 38500

Questão 29 - CMM/CMMI

Outro (especifique)

Os dados da pesquisa foram obtidos pelo software Survey Monkey e integrados pelo Excel ao sistema SPSS para tratamento estatístico.

As informações coletadas foram estatisticamente analisadas, por meio de análise descritiva, segmentação de perfis utilizando a análise de cluster (dendograma, intervalos de confiança simultâneos, Bonferroni - 
precisão logarítmica) e a correlação de Pearson (Figueiredo Filho \& Silva, 2009).

A análise descritiva foi desenvolvida considerando-se:

1) Frequência relativa (percentual) para cada valor de $X$.

$R f_{j}=\left(\frac{f_{j}}{W^{\prime}}\right) \times 100$

em que:

$$
W^{\prime}=\sum_{i=1}^{N V} f_{i}
$$

(soma de todas as categorias incluindo as declaradas como valores faltantes)

2) Frequência ajustada (percentual):

$$
A f_{j}=\left(\frac{f_{j}}{W}\right) \times 100
$$

em que:

$$
W=\sum_{i=1}^{N V} f_{i} k_{i}
$$

(soma de todas as categorias não faltantes)

e

$$
k_{i}=\left\{\begin{array}{l}
0 \\
1
\end{array}\right.
$$

0 , se Xi foi declarado como faltante, e 1, demais casos.

Para todo Xj declarado como faltante, uma frequência ajustada não é aplicada.

3) Frequência acumulativa (percentual)

$$
C f_{j}=\sum_{i=1}^{j} f_{i}
$$

Média 


$$
\bar{X}=\frac{\sum_{j=1}^{N V} f_{j} X_{j}}{W}
$$

Em algumas situações, a média é calculada como:

$$
M_{j}=\sum_{i=1}^{N V} f_{i}\left(X_{i}-\bar{X}\right)^{j} \quad j=2,3,4
$$

$$
\operatorname{EUCLID}(x, y)=\sqrt{\sum_{i}\left(x_{i}-y_{i}\right)^{2}}
$$

em que a fórmula significa a distância entre dois itens, $x$ e $y$, é a raiz quadrada da soma do quadrado das diferenças entre os valores dos itens.

A análise de correlação canônica é um modelo estatístico multivariado que facilita o estudo de inter-relações entre conjuntos de múltiplas variáveis dependentes e múltiplas variáveis independentes (Hair Jr, Black, Babin, Anderson \& Tatham, 2005).

Na sequência são apresentados os resultados obtidos na realização da pesquisa, bem como a discussão desses resultados.

\section{DISCUSSÃO E ANÁLISE DOS DADOS}

Neste tópico são apresentados e analisados os resultados obtidos durante o desenvolvimento da survey em todas as fases, assim como sugestões e melhorias enviadas pelos respondentes. Foram obtidas 55 respostas, 41 delas completas.

\subsection{TABULAÇÃO DO BLOCO 1 - CARACTERÍSTICAS DOS BANCOS E RESPONDENTES}

Na Tabela 1, observa-se que 58,5\% dos respondentes atuam em Tecnologia da Informação; 31,7\% em Governança de TI; 17,1\% em Segurança da Informação; 14,6\% em Planejamento Estratégico; 9,8 \%em Auditoria Interna; 7,3\% em Controles Internos; 7,3\% em Riscos; 4,9\% em Compliance e 4,9\% em Processos. 
Tabela 1: Área de atuação dos respondentes

\begin{tabular}{|l|c|c|}
\hline Área de Atuação: \\
\hline Opções de respostas & Percentual & Respondentes \\
\hline Auditoria Interna & $9,8 \%$ & 4 \\
Compliance & $4,9 \%$ & 2 \\
Controles Internos & $7,3 \%$ & 3 \\
Governança de TI & $31,7 \%$ & 13 \\
Planejamento Estratégico & $14,6 \%$ & 6 \\
Processos & $4,9 \%$ & 2 \\
Riscos & $7,3 \%$ & 3 \\
Segurança da Informação & $17,1 \%$ & 7 \\
Tecnologia da Informação & $58,5 \%$ & 24 \\
\hline Outro (especifique) & & 3 \\
\hline \multicolumn{2}{|c|}{ questionários respondidos } \\
\hline
\end{tabular}

$\mathrm{Na}$ Tabela 2, verifica-se que $34,1 \%$ dos respondentes são Gerentes/Gestores; 24,4\% Analistas; 17,1\% CIO (Chief Information Office); 9,8\% Superintendentes; 9,8 Supervisores/Coordenadores; e 4,9\% Diretores. Na opção "Outros", referente às áreas citadas, estão: Gerenciamento de Projetos e Customer Experience. Nesta opção "Outros", não há percentuais, uma vez que esta não é gerada pelo software, mas pode ser incluída na pesquisa, pois é fornecida no arquivo de integração da ferramenta.

Tabela 2: Cargos dos respondentes

\begin{tabular}{|l|c|c|}
\hline \multicolumn{2}{|l|}{ Cargo: } \\
\hline Opções de respostas & Percentual & Respondentes \\
\hline CEO & $0,0 \%$ & 0 \\
Vice-Presidente & $0,0 \%$ & 0 \\
Superintendente & $9,8 \%$ & 4 \\
CIO & $17,1 \%$ & 7 \\
CFO & $0,0 \%$ & 0 \\
CSO & $0,0 \%$ & 0
\end{tabular}


Diretor

Gerente / Gestor

Supervisor / Coordenador

Analista

Outro (especifique)

\begin{tabular}{l}
$4,9 \%$ \\
$4,1 \%$ \\
$9,8 \%$ \\
$4,4 \%$ \\
\hline
\end{tabular}

2

Verifica-se que $80 \%$ dos respondentes são gestores de áreas.

$\mathrm{Na}$ Tabela 3, nota-se que aparecem os seguintes tipos de bancos: múltiplo $(46,3 \%)$, comercial $(17,4 \%)$, investimento $(17,1 \%)$, financeira $(17,1 \%)$ e caixa $(2,4 \%)$.

Tabela 3: Tipo das instituições financeiras

Tipo:
Opções de respostas
Múltiplo
Comercial
Caixa
Investimento
Leasing
Financeira

Financeira

Nota-se que na Tabela 4, 82,9\% dos bancos são privados e $17,1 \%$ públicos.

Tabela 4: Origem das instituições financeiras

\begin{tabular}{|l|c|c|}
\hline Origem: \\
\hline Opções de respostas & Percentual & Respondentes \\
\hline Privado & $82,9 \%$ & 34 \\
Público & $17,1 \%$ & 7 \\
\hline \multicolumn{2}{|c|}{ questionários respondidos } \\
\hline
\end{tabular}


Na Tabela 5, observa-se que $46,3 \%$ dos bancos são nacionais, $26,8 \%$ estrangeiros, $12,2 \%$ nacionais com controle estrangeiro, $7,3 \%$ estaduais e $7,3 \%$ federais.

Tabela 5: Naturalidade das instituições financeiras

\begin{tabular}{|l|c|c|}
\hline Naturalidade \\
\hline Opções de respostas & Percentual & Respondentes \\
\hline Nacional & $46,3 \%$ & 19 \\
Nacional com participação estrangeira & $12,2 \%$ & 5 \\
Nacional com controle estrangeiro & $0,0 \%$ & 0 \\
Estrangeiro & $26,8 \%$ & 11 \\
Estadual & $7,3 \%$ & 3 \\
Federal & $7,3 \%$ & 3 \\
\hline \multicolumn{4}{|c|}{ questionários respondidos } \\
\hline
\end{tabular}

Na Tabela 6, apresenta-se o porte dos bancos em grande (61\%), médio-grande $(22 \%)$ e médio $(17,1 \%)$.

Tabela 6: Porte das instituições financeiras

Porte ( BNDES): Classificação pela Receita operacional bruta anual Microempresa - Menor ou igual a $R$ \$ 2,4 milhões Pequena empresa - Maior que $R$ \$ 2,4 milhões e menor ou igual a $R \$ 16$ milhões Média empresa - Maior que R\$16 milhões e menor ou igual a R\$90 milhões Médiagrande - Maior que R\$ 90 milhões e menor ou igual a R\$300 milhões Grande empresa - Maior que $\mathrm{R} \$ 300$ milhões

\begin{tabular}{|l|c|c|}
\hline Opção de resposta & Percentual & Respondentes \\
\hline Pequeno (Microempresa) & $0,0 \%$ & 0 \\
Pequeno Médio (Pequena Empresa) & $0,0 \%$ & 0 \\
Médio & $17,1 \%$ & 7 \\
Médio Grande & $22,0 \%$ & 9 \\
Grande & $61,0 \%$ & 25 \\
\hline
\end{tabular}

Fonte: BNDES (2014)

\subsection{RESULTADOS DA TABULAÇÃO DO BLOCO 2 - QUESTÕES SOBRE REQUISITOS PARA ATENDER A GOVERNANÇA DE TI POR MAIORES MÉDIAS}

Para obtenção dos resultados da tabulação do Bloco 2; foram adotados os seguintes indicadores: 
- mais aderentes: valores das maiores médias aritméticas dos requisitos com notas (0 a 10): não sei - 0; raríssimo - 1, 2 a 9; e muito utilizado - 10.

- menos aderentes: valores das menores médias aritméticas dos requisitos com notas (0 a 10): não sei - 0; raríssimo - 1, 2 a 9; e muito utilizado - 10.

No Gráfico 2, são apresentados os Resultados do Bloco 2, Requisitos para Governança de TI Mais e Menos Aderentes para os Cenários Atual e 2017.

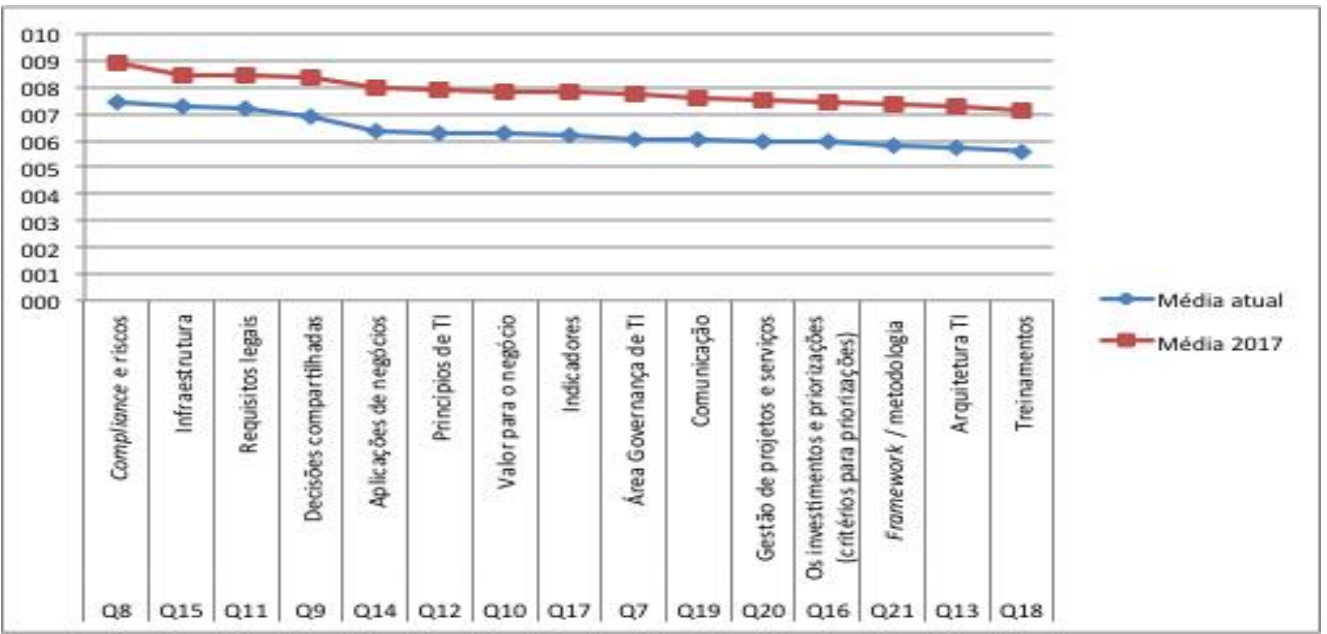

\section{Gráfico 2: Resultados dos requisitos para governança de TI mais e menos aderentes para os cenários atual e 2017}

O Grupo dos mais aderentes para o cenário atual: compliance e riscos (8), infraestrutura (15), requisitos legais (11) e decisões compartilhadas (9).

O Grupo dos menos aderentes para o cenário atual: treinamentos (18), arquitetura (13), framework / metodologia (21) e investimentos e priorizações (16).

O Grupo dos mais aderentes para 2017: compliance e riscos (8), decisões compartilhadas (9), infraestrutura (15) e requisitos legais (11).

O Grupo dos menos aderentes para 2017: treinamentos (18), framework/ metodologia (21), comunicação (19) e arquitetura (13).

Todas as médias de requisitos para governança de TI são crescentes do cenário atual para o cenário 2017. 


\subsection{RESULTADOS DA TABULAÇÃO DO BLOCO 3 - QUESTÕES SOBRE PRINCIPAIS PRÁTICAS DE GOVERNANÇA DE TI}

Para obtenção dos resultados desta tabulação do Bloco 3 foram adotados os seguintes indicadores:

- mais aderentes: valores das maiores médias aritméticas das práticas com notas (0 a 10): não sei - 0; inexistente - 1, 2 a 9; e totalmente implantado - 10.

- menos aderentes: valores das menores médias aritméticas das práticas com notas ( 0 a 10): não sei - 0; inexistente - 1, 2 a 9; e totalmente implantado - 10.

No Gráfico 3, são apresentados os resultados das médias dos grupos de práticas mais e menos aderentes para o Bloco 3, para os cenários atual e 2017.

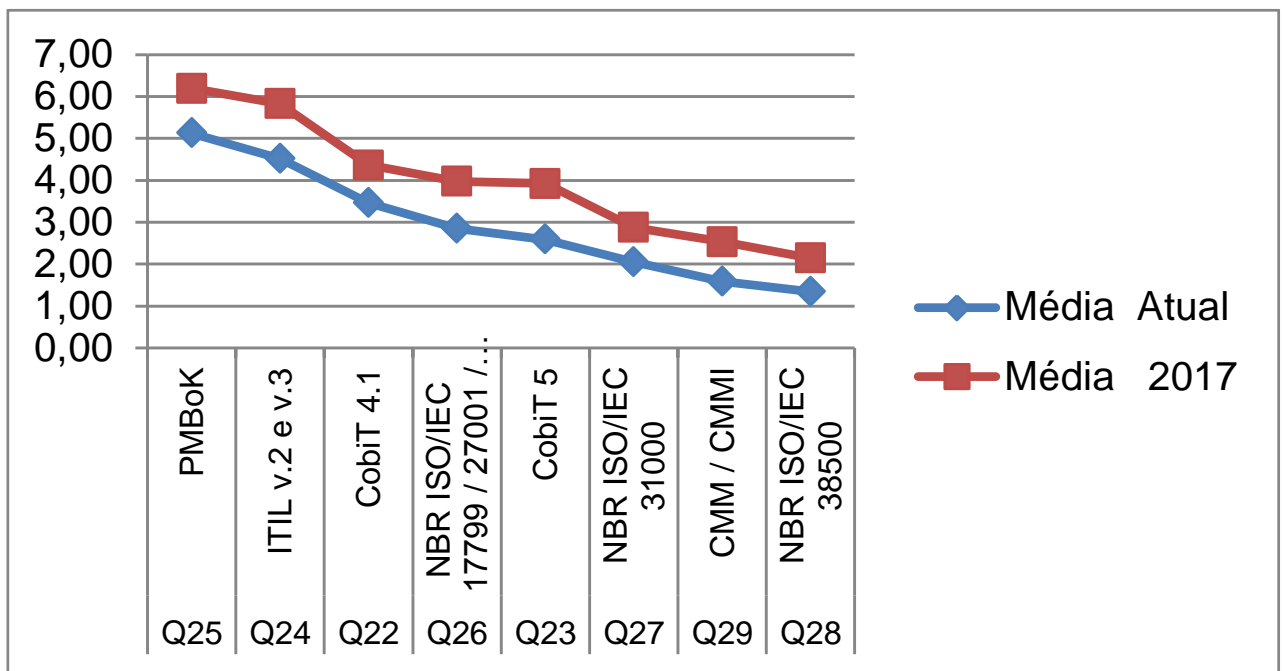

\section{Gráfico 3: Resultados das principais práticas para governança de TI por médias mais e menos aderentes para os cenários atual e 2017}

O Grupo dos mais aderentes para o cenário atual é formado por: PMBoK (25), ITIL v2 e v3 (24), COBIT 4.1 (22).

O Grupo dos menos aderentes para o cenário atual é formado por: NBR ISO/IEC 38500 (28), CMM/CMMI (29) e NBR ISO/IEC 310000 (27). 
O Grupo dos mais aderentes para o cenário 2017 é formado por: PMBoK (25), ITIL v2 e v3 (24) e COBIT 5 (22).

O Grupo dos menos aderentes para o cenário 2017 é formado por: NBR ISO/IEC 38500 (28), CMM/CMMI (29) e NBR ISO/IEC 310000 (27).

Todas as médias de práticas para governança de TI são crescentes do cenário atual para o cenário 2017.

\subsection{ANÁLISE DESCRITIVA - DEFINIÇÃO DE CLUSTERS}

O tratamento estatístico foi feito no sistema Statistical Package for the Social Sciences (SPSS). As informações coletadas foram estatisticamente analisadas por meio de análise descritiva, segmentação de perfis e também análise de cluster, a qual visa agrupar os dados em conjuntos, cujos elementos sejam os mais parecidos entre si ou os mais diferentes entre si.

No Gráfico 4, apresentam-se os resultados dos clusters do Bloco 2 Requisitos para Governança de TI - Grupo 1 (Fortes em Requisitos para Governança de TI) e Grupo 2 (Fracos em Requisitos para Governança de TI) nos Cenários Atual e 2017.

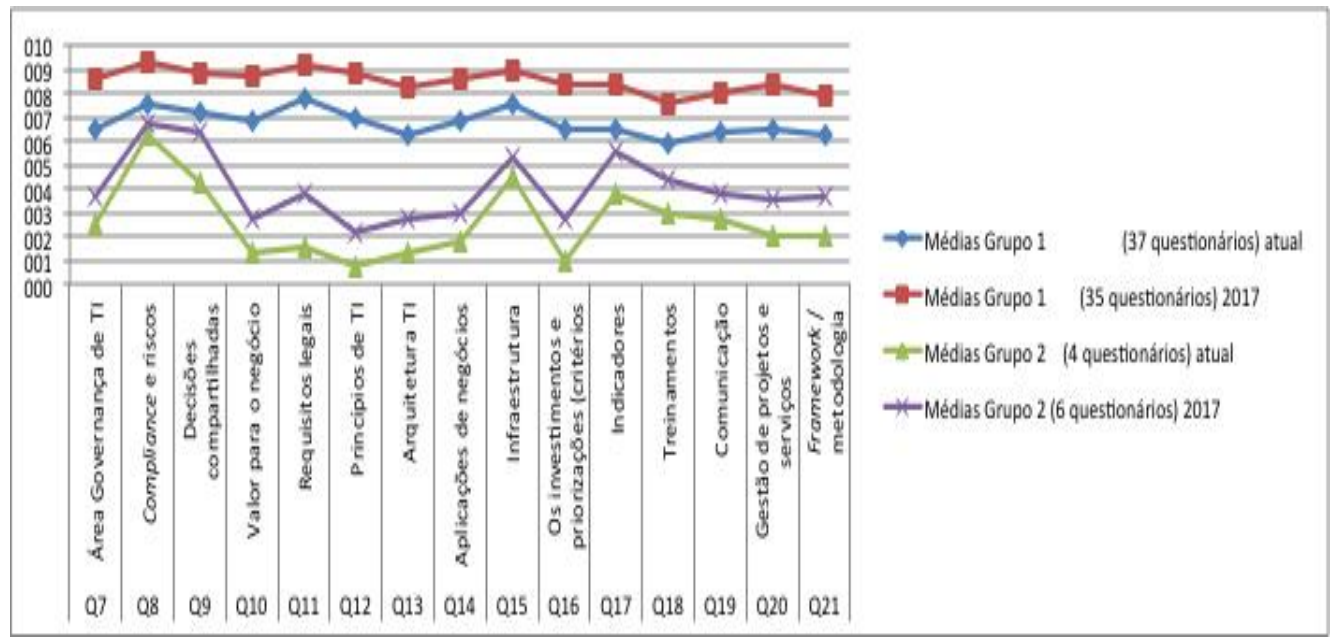

Gráfico 4: Resultados dos clusters do Bloco 2 - Requisitos para Governança de TI - Grupo 1 (Fortes em Requisitos para 


\section{Governança de TI) e Grupo 2 (Fracos em Requisitos para Governança de TI) nos cenários atual e 2017}

Os clusters do Grupo1 representam 37 questionários (90\%) dos 41 válidos da pesquisa. Já para o cenário 2017, os clusters do Grupo1 representam 35 questionários (85\%). Esses clusters consideraram as maiores médias e outras variáveis internas para formação desse Grupo1.

Os clusters do Grupo 2 representam quatro questionários (10\%) dos 41 válidos da pesquisa. Já para o cenário 2017, os clusters do Grupo2 representam seis dos questionários (15\%). Esses clusters consideraram as menores médias e outras variáveis internas para formação desse Grupo 2.

Todos os requisitos para governança de TI apresentam crescimento nas médias dos Grupos 1 e 2 dos cenários atuais para os cenários de 2017. Tais indicadores apontam tendências de as instituições financeiras continuarem a investir de forma crescente nos requisitos para governança de TI.

Os requisitos de compliance e riscos (Q8), decisões compartilhadas (Q9) e infraestrutura (Q15) apresentam uma média mais elevada do que os demais requisitos do Grupo2 no cenário atual e de 2017. Tais critérios também foram igualmente priorizados nas maiores médias de requisitos para o cenário atual e o de 2017.

Todos os requisitos para governança de TI apresentam crescimento nas médias dos Grupos 1 e 2 dos cenários atuais para os cenários de 2017. Tal fato mostra a tendência de as instituições financeiras continuarem a investir, de forma crescente, nos requisitos para governança de TI.

No Gráfico 5, apresentam-se os resultados dos Clusters do Bloco 3 Práticas para Governança de TI - Grupo 3 (Fracos em Práticas para a Governança de TI ) e Grupo 4 (Fortes em Práticas para a Governança de TI) nos cenários atual e 2017 


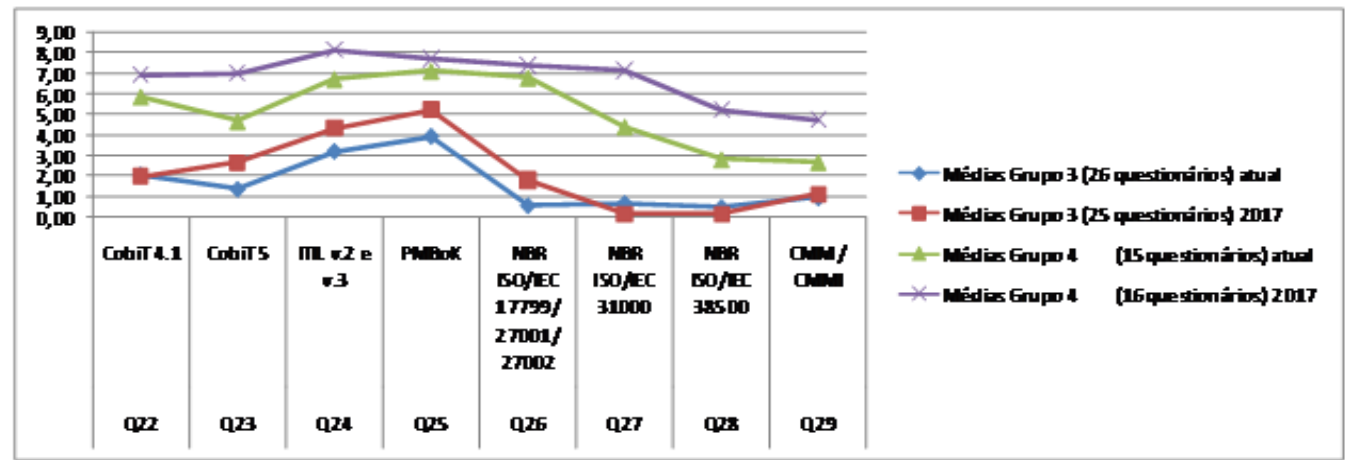

NÃO SEI

Cenário Atual

Cenário 2017

$\begin{array}{lll}\text { COBIT 4.0 } & 36,6 \% & 39 \% \\ \text { COBIT 5 } & 39 \% & 36,6 \% \\ \text { ITL v.2 e v.3 } & 24,4 \% & 24,4 \% \\ \text { PMBOK } & 12,2 \% & 14,6 \% \\ \text { NBR ISO/IEC 1779g/27001/ 27002 } & 46,3 \% & 43,9 \% \\ \text { NBR ISOIEC 31000 } & 53,7 \% & 53,7 \% \\ \text { NBR ISO/EC 38500 } & 61 \% & 61 \% \\ \text { CMM CMMI } & 39 \% & 39 \%\end{array}$

\section{Gráfico 5: Resultados dos clusters do Bloco 3 - Práticas para Governança de TI - Grupo 3 (Fracos em Práticas para a Governança de TI ) e Grupo 4 (Fortes em Práticas para a Governança de TI) nos cenários atual e 2017}

Os clusters do Grupo 3 representam 26 questionários (64\%) dos 41 válidos da pesquisa. Já para o cenário 2017, os clusters do Grupo 3 representam 25 questionários (61\%). Esses clusters consideraram as menores médias e outras variáveis internas para formação desse Grupo3.

Os clusters do Grupo 4 representam 15 questionários (36\%) dos 41 válidos da pesquisa. Já para o cenário 2017, os clusters do Grupo 4 representam 16 questionários (39\%). Esses clusters consideraram as maiores médias e outras variáveis internas para formação desse Grupo 4.

No Grupo 3, todas as práticas para governança de TI apresentam crescimento nas médias do cenário atual para o cenário de 2017 , exceto o COBIT 4, pois há crescimento na nova versão COBIT 5. Também decrescem as médias das práticas NBR ISO/IEC 31000 e NBR ISO/IEC 38500. Tal indicador aponta uma tendência de as instituições financeiras selecionadas para este Grupo (61\%) continuarem a investir, de forma crescente, nas práticas para governança de TI, porém, notam-se médias mais baixas (abaixo de 5 , exceto o PMBoK - Q25 $(5,24)$ ) e com um número expressivo de notas zeros - "não sei". 
No Grupo 4, todos os requisitos para governança de TI apresentam crescimento nas médias dos cenários atuais para os cenários de 2017. Tais indicadores apontam tendências de as instituições financeiras continuarem a investir de forma crescente nas práticas para governança de TI. Destacamse duas práticas com médias menores: CMM/CMMI - Q29 $(4,75)$ e NBR ISO/IEC 38500 - Q28 (5,25). As demais práticas apresentam médias entre 6,94 e 8,13 para o cenário de 2017.

\section{CONSIDERAÇÕES FINAIS}

Neste estudo buscaram-se respostas para atender à questão de pesquisa elaborada: Quais requisitos e práticas de governança de TI os bancos de varejo no Brasil adotaram até 2014 e continuarão adotando ou implementarão até 2017?

Intencionou-se avaliar, nos bancos de varejo no Brasil, o histórico da utilização de requisitos e práticas de Governança de TI até 2014 e suas projeções até 2017. Igualmente, buscou-se não só verificar a aderência e os motivos da utilização de requisitos e práticas para governança de TI nos bancos de varejo pesquisados, como também, contribuir para o registro das informações históricas em relação ao assunto para pesquisas futuras.

Como síntese dos principais resultados obtidos com a pesquisa realizada, apresentam-se os seguintes resultados:

1) Das médias dos requisitos para governança de TI, obtiveram-se, em ordem decrescente, dos:

- mais aderentes para o cenário atual: compliance e riscos, infraestrutura, requisitos legais e decisões compartilhadas;

- mais aderentes para 2017: compliance e riscos, decisões compartilhadas, infraestrutura e requisitos legais;

- menos aderentes para o cenário atual: treinamentos, arquitetura, framework/metodologia e investimentos e priorizações;

- menos aderentes para 2017: treinamentos, framework/metodologia, comunicação e arquitetura. 
Tais resultados mostram as tendências da priorização das instituições financeiras não só nas questões de segurança, riscos, compliance, como também na questão de suportar o crescimento dos negócios com a ampliação da infraestrutura tecnológica.

Outro aspecto que se destacou foi a maior aderência do requisito decisões compartilhadas, mostrando a tendência de os profissionais de TI trabalharem muito próximos às áreas de negócios para atender aos projetos estratégicos das empresas.

Os requisitos menos aderentes citados para os cenários atual e 2017 demonstram a necessidade de as empresas trabalharem mais nos treinamentos, arquitetura de TI, comunicação e frameworks (práticas) e metodologias.

2) Nos clusters de requisitos para governança de TI, obtiveram-se as médias, em ordem decrescente, dos:

- $\quad$ fortes em Requisitos para a Governança de TI para o cenário atual: requisitos legais, infraestrutura, compliance e riscos e decisões compartilhadas;

- fortes em Requisitos para a Governança de TI para o cenário 2017: compliance e riscos, requisitos legais, infraestrutura e decisões compartilhadas;

- fracos em Requisitos para a Governança de TI para o cenário atual: arquitetura de TI, valor para o negócio, investimentos e priorizações e princípios para TI;

- fracos em Requisitos para a Governança de TI para o cenário 2017: investimentos e priorizações, valor para o negócio, arquitetura de TI e princípios para TI.

Todos os requisitos para governança de TI apresentam crescimento nas médias dos "Fortes em Requisitos para a Governança de TI" (90\% dos questionários no cenário atual e $85 \%$ em 2017) e também crescimento nas médias dos "Fracos em Requisitos para a Governança de TI" (10\% dos questionários no cenário atual e 15\% no cenário 2017). Tais indicadores apontam tendências de as instituições financeiras continuarem a investir, de forma crescente, nos requisitos para governança de TI. 
Os resultados dos Fortes em Requisitos para a Governança de TI para os cenários atual e 2017 demonstram a tendência de priorizações para a questão de segurança; atender aspectos legais e riscos; decisões compartilhadas e infraestrutura, em conformidade, também, com os resultados das médias dos requisitos para governança de TI mais aderentes apresentadas nesta pesquisa.

Os Fracos em Requisitos para a Governança de TI e motivos das menores médias neste conjunto poderiam ser avaliados em novas pesquisas, como também os Fracos em Requisitos para a Governança de TI representaram um número pequeno em relação ao total dos questionários desta pesquisa (quatro questionários para o cenário atual e seis questionários para o cenário 2017).

3) Das médias das práticas para governança de TI, obtiveram-se, em ordem decrescente, dos:

- mais aderentes para o cenário atual: PMBoK, ITIL v2 e v3 e, COBIT 4.1;

I- $\quad$ mais aderentes para 2017: PMBoK, ITIL v2 e v3 e, COBIT 4.1;

- menos aderentes para o cenário atual: NBR ISO/IEC 38500, CMM/CMMI e NBR ISO/IEC 310000;

- $\quad$ menos aderentes para 2017: NBR ISO/IEC 38500, CMM/ CMMI e NBR ISO/IEC 310000.

Tais resultados indicam as tendências de implementação de práticas, como o PMBoK, que têm crescido no cenário mundial, inclusive com atualizações constantes e considerando as questões humanas, como foi a criação da nova área de conhecimento gestão de stakeholders em 2012 pelo PMI.

O ITIL também apresenta estatísticas de crescimento com sua estrutura integrada e voltada ao gerenciamento completo de serviços.

O COBIT 5, lançado em 2012, também apresenta tendência de crescimento de implementações, pois trata-se de uma plataforma integrada para atender aos requisitos para governança de TI.

Em relação às práticas de governança para TI menos aderentes, houve um número expressivo de respostas com nota 0 (não sei ) nos 41 
questionários respondidos, que influenciaram no decréscimo das médias, conforme detalhado na pesquisa. Neste caso, há indicação da necessidade de novas pesquisas para não só verificar os motivos que causaram essa situação, mas também avaliar os motivos das práticas menos aderentes.

4) Nos clusters das práticas para governança de TI, obtiveram-se as médias, em ordem decrescente, dos:

- fortes em Práticas para a Governança de TI para o cenário atual: PMBoK, NBR ISO/IEC 177999/27001/27002, ITIL v2 e v3 e COBIT 4.1;

- fortes em Práticas para a Governança de TI para o cenário 2017: ITIL v2 e v3 PMBoK, NBR ISO/IEC 177999/27001/27002, ISO31000, COBIT 5;

- fracos em Práticas para a Governança de TI para o cenário atual: PMBoK, ITIL v2 e v3 e COBIT 4.1;

- fracos em Práticas para a Governança de TI para o cenário 2017: PMBoK, ITIL v2 e v3, COBIT 5 e COBIT 4.1.

Nos Fracos em Práticas para a Governança de TI (26 questionários para o cenário atual e 25 para o cenário 2017), todas as práticas para governança de TI apresentam crescimento nas médias do cenário atual para o cenário de 2017, exceto o COBIT 4, pois há crescimento para a nova versão do COBIT 5. Decrescem apenas as médias das práticas NBR ISO/IEC 31000 e NBR ISO/IEC 38500. Tal indicador aponta uma tendência de as instituições financeiras selecionadas para este grupo continuarem a investir, de forma crescente, nas práticas para governança de TI, porém, notam-se médias menores (abaixo de 5 exceto o PMBoK $(5,24)$ ) e com um número expressivo de notas 0 - "não sei", conforme já apresentado.

As práticas NBR ISO/IEC 177999/27001/27002 e NBR ISO 31000 também se destacaram entre as médias superiores, mostrando tendências já apontadas para priorização em segurança da informação e riscos em instituições financeiras.

Nos Fortes em Práticas para a Governança de TI (15 questionários para o cenário atual e 16 para o cenário 2017), todas as práticas para governança de TI apresentam crescimento nas médias dos cenários atuais para os cenários de 2017. Tais indicadores apontam tendências de as 
instituições financeiras continuarem a investir, de forma crescente, nas práticas para governança de TI. Destacam-se duas práticas com médias menores: CMM/CMMI e NBR ISO/IEC 38500.

Também procurou-se identificar características similares para bancos e respondentes com maiores e menores médias dentro dos resultados dos clusters de requisitos para governança de TI e práticas para governança de TI; nos comparativos entre os requisitos e as práticas com maiores e menores médias, não houve segmentações significativas de características de bancos e respondentes para os conjuntos, isto é, tanto nos grupos fortes como nos fracos em Requisitos para Governança de TI e grupos fortes e fracos em Práticas para Governança de TI.

Os resultados desta pesquisa estão em linha com os trabalhos desenvolvidos pelos autores pesquisados na fundamentação teórica, mostrando que o segmento bancário continua investindo de forma crescente em tecnologia da informação e a governança TI permanece como requisito necessário para o desenvolvimento seguro para os negócios.

Como exemplo, no histórico da utilização de requisitos e práticas de Governança de TI até 2014 e suas projeções até 2017, Cantón e Galegale (2008), nos resultados de sua pesquisa, avaliaram os processos do COBIT em 2008 e previsões para 2010. Foi atribuída maior prioridade a: atender requisitos legais, segurança da informação, compliance e gerenciamento de riscos para o cenário de 2008; já no cenário para 2010, gerenciamento de riscos, segurança, plano de continuidade de negócios, controles internos e atendimento a requisitos legais. Tais resultados confirmam tendências de utilização desses mesmos requisitos nos bancos na pesquisa atual para o cenário até 2014 e projeções para 2017.

Neste trabalho, apontaram-se os resultados de requisitos e práticas para governança de TI para o cenário atual e projeções para 2017, conforme a questão da pesquisa.

Os resultados desta pesquisa também levam a possíveis tendências pelos respondentes gestores (aproximadamente 75\%) e analistas (25\%) para a necessidade de maior visibilidade das frequências de implementações dos requisitos individuais ou parciais para atender à governança de TI, do que a implementação de práticas e metodologias para 
atender às necessidades das empresas de forma integrada. As áreas de atuação dos respondentes também foram diversas, destacando-se as maiores respondentes: TI e Governança de TI, mas um estudo mais detalhado no futuro poderia avaliar as possíveis variações entre as respostas de áreas de atuações diferentes.

Igualmente, o índice de respostas "não sei" para práticas foi elevada; assim, os requisitos e as práticas com médias menos aderentes para governança de TI e seus motivos poderiam ser mais bem avaliados em novos trabalhos.

\section{REFERÊNCIAS}

Albertin, R. M. M., \& Albertin, A. L. (2010). Estratégias de governança de tecnologia da informação: estruturas e práticas. Rio de Janeiro: Elsevier.

Appolinário, F. (2011). Dicionário de metodologia científica. Um guia para a produção do conhecimento científico (2a ed.). São Paulo: Atlas.

Associação Brasileira de Normas Técnicas - ABNT. (2005). ABNT NBR ISO/IEC 27002 - Tecnologia da informação - Técnicas de segurança Código de prática para a gestão de segurança da informação. Recuperado em 1 de setembro, 2013, de https://pt.scribd.com/doc/51112696/NBRISO-27002-para-impressao

Associação Brasileira de Normas Técnicas. (2012, junho). ABNT NBR ISO/IEC 38500:2009. Boletim ABNT, 10(118). Recuperado em 1 de setembro, 2013, de http://www.rsirius.uerj.br/pdfs/edicao-770_ABNT.pdf

Banco Central do Brasil - BCB. (2014). Relação de instituições em funcionamento no país (transferência de arquivos). Recuperado em 2 de fevereiro, 2014, de http://www.bcb.gov.br/?RELINST

Banco Nacional de Desenvolvimento Social - BNDES. (2014). Porte de empresa 2013. Recuperado em 3 de maio, 2014, de http://www.bndes.gov.br/SiteBNDES/bndes/ bndes_pt/Institucional/Apoio_Financeiro/porte.htm

Barros, A. J. da S., \& Lehfeld, N. A. de S. (2007). Fundamentos de metodologia científica (3a ed.). São Paulo: Pearson: Prentice Hall. 
Bertram, D. (2009). Likert scales. A technique for the measurement of attitudes. Archives of Psychology, 22(140), 1-55. Recuperado em 2 de abril, 2013, de http://poincare.matf.bg.ac.rs/ kristina/topic-danelikert.pdf

Bussab, W., \& Morettin, P. A. (2002). Estatística básica (5a ed.). São Paulo: Saraiva.

Cantón, E., \& Galegale, N. V. (2008). Pesquisa revela visão geral e tendências da governança de TI nas instituições financeiras no Brasil. São Paulo: Centro Estadual de Educação Tecnológica Paula Souza. Recuperado em 1 de março, 2013, de http://www.centropaulasouza.sp.gov.br/pos-graduacao/workshop-depos-graduacao-e-pesquisa/anais/2008/comunicacao-oral/informacaoaplicadas/pesquisa\%20revela.visao. geral.pdf

Capability Maturity Model Integration - CMMI. (2013). Wibas CMMI Browser. Recuperado em 18 de maio, 2013, de http://www.cmmi.de/\#el=CMMI/0/HEAD/folder/folder

Ciab Febraban (2012). Relatório bancário: governança de TI \& outsourcing nos bancos. Recuperado em 4 de abril, 2013, de http://www.relatoriobancario.com.br/rb/coluna_esquerda/canais/eventos /eventos_realizados/governanca_valoriza_a_ti

Ciab Febraban (2013). Pesquisa Febraban de tecnologia bancária 2013 - O setor bancário em números. Recuperado em 4 de abril, 2013, de http://www.febraban.org.br/7R

of7SWg6qmyvwJcFwF7I0aSDf9jyV/sitefebraban/Pesquisa\%20Febraban\% 20de\%20 Tecnologia\%20Banc\%E1ria\%202013.pdf

Cordenonsi, J. (2004). Um modelo de administração da tecnologia da informação. In D'Andrea, E. R. P. Parte 13. In A. L. Albertin, \& R. M. de M. Albertin (Orgs.),Tecnologia de informação. São Paulo: Atlas.

Federação Brasileira de Bancos - Febraban (2013a). Portal de Informações do Setor. Recuperado em 2 de abril, 2013, de http://www.febraban.org.br

Federação Brasileira de Bancos - Febraban. Lista de Bancos (2013b). Recuperado em 1 de junho, 2013, de http://www.buscabanco.org.br/Agencias Bancos.asp

Fernandes, A. A., \& Abreu, V. F. (2010). Implantando a governança de TI: da estratégia à gestão dos processos e serviços (3a ed.). São Paulo: Brasport.

Figueiredo Filho, D. B., \& Silva Júnior, J. A. (2009). Desvendando os mistérios do coeficiente de correlação de Pearson ( $r$ ). Revista Política Hoje, 18(1), 115-146. 
Fitzpatrick, E. W. (2005). Planning and implementing. IT portfolio management: maximizing the return on information technology investments. Gaithersburg: It Economics Corporation.

Groves, R., Flowlr, F., Couper, M., Lepkowski, J., Singer, E., \& Tourangeau, R. (2004). Survey methodology. New York: Wiley Interscience.

Hair Jr., J. F., Black, W. C., Babin, B. J., Anderson, R. E., \& Tatham, R. L. (2005). Análise multivariada de dados (5a ed., A. S. Sant'Anna e A. Chaves Neto Trad.). Porto Alegre: Bookman.

Harzing, A. W. (2007). Publish or perish. Recuperado em 4 de abril, 2013, de http://www.harzing.com/pop.htm

Information Technology Infrastructure Library - ITIL (2007). Recuperado em 15 de maio, 2013, de http://www.itil-officialsite.com/

Information Technology Service Management Forum - ITSMF. (2013). Recuperado em 15 de maio, 2013, de http://www.itsmf.com.br/portal/?page_id $=74$

IT Governance Institute - ITGI (2003). Board briefing on IT governance (2nd ed.). United States of America: ITGI.

IT Governance Institute - ITGI. (2005). COBIT: Control Objectives for Information and related Technology. United States of America: ITGI.

IT Governance Institute - ITGI. (2012). COBIT: Control Objectives for information and related Technology. United States of America: ITGI.

IT Governance Institute, Information Systems Audit and Control Association - ITGI-ISACA. (2011). Global status report on the governance of enterprise IT - GEIT. 2011. Recuperado em 3 junho, 2014 de http://www.isaca.org/knowledge-

center/research/researchdeliverables/pages/global-status-report-on-thegovernance-of-enter prise-it-geit-2011.aspx.

IT Governance Institute, Information Systems Audit and Control Association - ITGI-ISACA. (2012). Governança de TI Empresarial (GEIT). Levantamento 2012. Recuperado em 5 novembro, 2013 de http://www.isaca.org/pages/2012-governance-of-enterprise-it-geitsurvey.aspx.

Kaplan, R. S., \& Norton, D. P. (2006). Alinhamento: utilizando o balanced scorecard para criar estratégias corporativas. Rio de Janeiro: Elsevier.

Luftman, J. N. (2000, December). Assessing business-IT alignment maturity. Comunications of the Association for Information Systems, 4, 2-49.

Luftman, J. N. (2003). Competing in the information age: align in the sand. Oxford: Oxford University Press. 
Luftman, J., Kempaiah, R., \& Nash, E. (2006). Key issues for IT executives 2005. MIS Quarterly Executive, 5(2), 81-99.

Lunardi, G. L. (2008). Um estudo empírico e analítico do impacto da governança de TI no desempenho organizacional. Tese de Doutorado, Universidade Federal do Rio Grande do Sul: Porto Alegre, RS, Brasil.

Meirelles, F. S.(2004). Investimentos e indicadores nas empresas: evolução e tendências. In A. L. Albertin, \& R. M. M. Albertin, Tecnologia de informação. São Paulo: Atlas.

Office of Government Commerce - OGC (2008). ITIL: Information Technology Infrastructure Library. Service Support.

Peterson, R. (2004a, Fall). Crafting information technology governance. Information Systems Management, 21(4), 7-22.

Peterson, R. (2004b). Integration strategies and tactics for information technology governance. In W. Van Grembergen, Strategies for information technology governance. Hershey: Idea Group Publishing.

Project Management Institute - PMI (2013). PMI. Capítulo São Paulo Brasil. Recuperado em 3 de maio, 2013, de http://www.pmisp.org.br/institucional/pmi/o-instituto

Project Management Institute - PMI (2012). A guide to the Project Management Body of Knowledge (PMBOK Guide) (5th ed.). Project Management Institute.

Ruzbacki, T. (2004). Sarbanes-Oxley, IT governance and enterprise change management. London: CNET Network.

Software Engineering Institute - SEI. (2013). Carnegie Mellon. CMMI. Recuperado em 18 de maio, 2013, de http://www.sei.cmu.edu/library/searchresults.cfm?q=CMMI\%20portugue s\&btnG $=$ GO\&start $=10 \&$ scopeType $=0 \&$ site $=$ library_new $\&$ num $=10 \&$ sort $=d$ ate:D:L: d1\&islibrarysearch $=1 \&$ client=newfrontend\&areasofwork $=\& d o c t i t \mid$ $\mathrm{e}=$ \&pubid $=$ \&author $=$ PDF

Valor Econômico (2013). Os 100 Maiores Bancos. Ranking dos 100 Maiores. Valor 1000. 2013. Recuperado em 3 maio, 2014 de http://www.valor.com.br/valor1000/2013/ ranking100maiores.

Van Grembergen, W., De Haes, S., \& Guldentops, E. (2004). Structures, processes and relational mechanisms for IT governance. In W. Van Grembergen, Strategies for information technology governance. Hershey: Idea Group Publishing.

Vanti, N. (2002). Da bibliometria à webometria: uma exploração conceitual dos mecanismos utilizados para medir o registro da informação e a difusão do conhecimento. Ciência da Informação, 31(2), 152-162. 
Venkatraman, N. (1994, Winter). IT-enabled business transformation: from automation to business scope redefinition. Sloan Management Review, $35(2), 72-87$.

Webb, P., Pollard, C., \& Ridley, G. (2006). Attempting to define IT governance: wisdom. Proceedings of the Hawaii International Conference on System Sciences, 39, Hawaii, USA.

Weill, P. (2004). Don't just lead govern: how top-performing firms govern IT. MIS Quarterly Executive, 3(1), 1-17.

Weill, P., \& Ross, J. W. (2004). IT governance: how top performers manage IT decision rights for superior results. Boston: Harvard Business School Press.]

Weill, P., \& Ross, J. W. (2006). Governança de TI: tecnologia da informação. São Paulo: Makron Books.

Weill, P., \& Ross, J. W. (2006). IT governance in one page. Cambridge: MIT Sloan School of Management.

Weill, P., \& Broadbent, M. (1998). Leveraging the new infrastructure: how market leaders capitalize on information technology. Watertown: Harvard Business School Press. 